\title{
First-Principles Modeling of X-Ray Absorption Spectra Enlightens the Processes of Scandium Sequestration by Iron Oxides
}

\author{
M. CHASSÉ ${ }^{1 *}$, M. BLANCHARD ${ }^{2}$, D. CABARET ${ }^{1}$, A. \\ JUHIN $^{1}$, D. VANTELON ${ }^{3}$ AND G. CALAS ${ }^{1}$
}

${ }^{1}$ Sorbonne Université, CNRS, IMPMC, Paris, France (*correspondence: mathieu.chasse@normalesup.org)

${ }^{2}$ GET, CNRS, Université de Toulouse, France

${ }^{3}$ SOLEIL synchrotron, Gif-sur-Yvette, France

Scandium is often associated with iron oxides in the environment. Despite the use of scandium as a geochemical tracer and the existence of world-class supergene deposits, uncertainties on speciation obscure the processes governing its sequestration and concentration.

To investigate these processes, we use first-principles approaches to interpret experimental $K$-edge $\mathrm{X}$-ray absorption near-edge structure spectra of scandium either incorporated in or adsorbed on goethite and hematite, at concentrations relevant for the environment[1]. This modeling helps to interpret the characteristic spectral features, providing key information to determine scandium speciation when associated with iron oxides. We show that scandium is substituted into iron oxides at low concentration without modifying the crystal structure. When scandium is adsorbed onto iron oxide surfaces, the process occurs through outer-sphere complexation with a reduction in the coordination number of the hydration shell. Considering available $\mathrm{X}$-ray absorption spectra from laterites, the present results confirm that scandium adsorption onto iron oxides is the dominant mechanism of sequestration in these geochemical conditions. This speciation explains efficient scandium recovery through mild metallurgical treatments of supergene lateritic ores. The specificities of scandium sorption mechanisms are related to the preservation of adsorbed scandium in million-years old laterites.

These results demonstrate the emerging ability to precisely model fine X-ray absorption spectral features of trace metals associated with mineral phases relevant to geological contexts. It opens new perspectives to accurately determine trace metals speciation from high-resolution spatially-resolved X-ray absorption near-edge structure spectroscopy in order to constrain the molecular mechanisms controlling their concentration processes.

[1] Chassé et al. (2020) American Mineralogist, in press (10.2138/am-2020-7308). 